\title{
Editorial \\ Machine Learning Applications in Power System Condition Monitoring
}

\author{
Bruce Stephen (iD
}

check for

updates

Citation: Stephen, B. Machine

Learning Applications in Power

System Condition Monitoring.

Energies 2022, 15, 1808. https://

doi.org/10.3390/en15051808

Received: 14 February 2022

Accepted: 24 February 2022

Published: 1 March 2022

Publisher's Note: MDPI stays neutral with regard to jurisdictional claims in published maps and institutional affiliations.

Copyright: (c) 2022 by the author. Licensee MDPI, Basel, Switzerland. This article is an open access article distributed under the terms and conditions of the Creative Commons Attribution (CC BY) license (https:// creativecommons.org/licenses/by/ $4.0 /)$.
Department of Electronic and Electrical Engineering, University of Strathclyde, Glasgow G1 1XW, UK; bruce.stephen@strath.ac.uk

While machine learning has made inroads into many industries, power systems have some unique application constraints and barriers that have motivated the creation of this Special Issue on their applications in condition monitoring. In recent years, power systems have undergone a once-in-a-generation transformation to accommodate lowcarbon technologies while supporting ever-higher expectations of their service level. New technology and legacy plants are expected to coexist seamlessly on networks that are being used outside of their original design specification through schemes such as dynamic rating. Condition monitoring is a possible way to facilitate this, but only if data can be reduced to an interpretable form, which is where machine learning offers leverage. Supporting existing domain expertise with higher-resolution operational insight unlocks the possibility for investment in condition monitoring, and here the design of appropriate analytics and automation is key. No matter the application-generation, transmission, distribution, or end use-power assets are diverse, and their performance is reflective of their health and operating environment.

While many areas of machine learning applications have data and exemplar cases in abundance, data acquisition costs in power systems are not trivial.

The authors contributing to this issue have recognized this, and have contributed works that offer practical value by harnessing domain expertise in analytic design, repurposing existing datasets and utilizing approaches that accommodate uncertainty in limited observations.

Dao [1] contributes an online anomaly-detection method for recognizing degradation onset in wind turbines, utilizing readily available Supervisory Control and Data Acquisition (SCADA) data and circumventing the need for historical fault exemplars by identifying structural breaks in monitoring data. Distribution networks are diverse and difficult to generalize modelling assumptions from; accordingly, Tsioumpri [2] contributes a data-driven approach to fault prediction based on routinely collected regulatory fault time/location data and publicly available weather observations. The machine learning-based mapping between weather cause and fault effect is demonstrated via a case study in the northeast of England, where a challenging mix of urban and rurally situated infrastructure offers both underground cable and overhead line fault test cases. Returning to wind generation, Corley [3] also utilizes SCADA data to contrast and combine physics and data-driven predictive models for capturing fault behavior in the month prior to failure. Emphasizing the continued importance of thermal-generation technology, Li [4] presents the application of an advanced autoencoder to identify early-stage plant degradation through changes in operating data patterns. Through residual analysis of predicted and actual temperature observations in the plant, the faulted case is shown to be distributed differently. In the first of two works contributed by McKinnon [5], a number of anomaly detection models designed for the use of operational SCADA data are presented. An important feature of these models is the minimal amount of training data required for their useful operation. From an asset-management perspective, this allows a sample across machines in a fleet to be assessed to pick out an underperforming plant. The second of McKinnon's [6] contributions 
focuses on modelling normal behavior to a high degree of fidelity in order to capture faults as deviations from expected performance. Again, the practicalities of having sufficient training data are highlighted, via a formal treatment of the effects of model order, training size and data resolution. Concluding this Special Issue, Tang [7] provides a shipboard power system prognostic application with a remaining useful-life estimator for battery energy storage. The contribution is demonstrated on condition monitoring data from an operational vessel, providing the ideal charge schedule to maintain battery asset health.

Machine learning will continue to be an important part of the condition-monitoring process, and with data acquisition becoming more straightforward and less expensive, the applicability of models will increase. In the meantime, as the works in this Special Issue have shown, the keys to a successful application are: to leverage domain expertise to inform the choice of model covariates with the greatest predictive power; to formulate physics-informed input features; and, importantly, to choose appropriate metrics that not only validate model performance but also its engineering application value.

Funding: This research received no external funding.

Institutional Review Board Statement: Not applicable.

Informed Consent Statement: Not applicable.

Data Availability Statement: Not applicable.

Conflicts of Interest: The author declares no conflict of interest.

\section{References}

1. Dao, P.B. A CUSUM-Based Approach for Condition Monitoring and Fault Diagnosis of Wind Turbines. Energies 2021, 14, 3236. [CrossRef]

2. Tsioumpri, E.; Stephen, B.; McArthur, S. Weather Related Fault Prediction in Minimally Monitored Distribution Networks. Energies 2021, 14, 2053. [CrossRef]

3. Corley, B.; Koukoura, S.; Carroll, J.; McDonald, A. Combination of Thermal Modelling and Machine Learning Approaches for Fault Detection in Wind Turbine Gearboxes. Energies 2021, 14, 1375. [CrossRef]

4. Li, X.; Liu, J.; Li, J.; Li, X.; Yan, P.; Yu, D. A Stacked Denoising Sparse Autoencoder Based Fault Early Warning Method for Feedwater Heater Performance Degradation. Energies 2020, 13, 6061. [CrossRef]

5. McKinnon, C.; Carroll, J.; McDonald, A.; Koukoura, S.; Infield, D.; Soraghan, C. Comparison of New Anomaly Detection Technique for Wind Turbine Condition Monitoring Using Gearbox SCADA Data. Energies 2020, 13, 5152. [CrossRef]

6. McKinnon, C.; Turnbull, A.; Koukoura, S.; Carroll, J.; McDonald, A. Effect of Time History on Normal Behaviour Modelling Using SCADA Data to Predict Wind Turbine Failures. Energies 2020, 13, 4745. [CrossRef]

7. Tang, W.; Roman, D.; Dickie, R.; Robu, V.; Flynn, D. Prognostics and Health Management for the Optimization of Marine Hybrid Energy Systems. Energies 2020, 13, 4676. [CrossRef] 